\title{
5 Synopsis:
}

6 Current building regulations for design against progressive collapse normally use prescriptive rules and risk-

7 based qualitative scales which are insufficient to cover current needs in design. Structural robustness of concrete

8 flat slab structures is examined using different theoretical models to capture the dynamic behavior under

9 accidental events. In such extreme events, the large dynamic reactions at the connections could potentially lead

10 to punching and progressive collapse. Punching formulae based on load-deformation response relationships such

11 as the Critical Shear Crack Theory (CSCT) are particularly useful in dynamic situations. The Ductility-Centred

12 Robustness Assessment developed at Imperial College London is also used in this paper to derive simple design

13 formulae to assess punching of adjacent columns in the sudden column removal scenario which is commonly 14 adopted in practice. The approach can be extended to assess flat slab systems upon considering membrane 15 action in the slab and post-punching behavior in the connections. Analytical models for tensile membrane are 16 used in combination with the CSCT to demonstrate that the tying forces required in codes of practice cannot be

17 achieved without prior punching of the connections. It is also shown that numerical modelling of post-punching

18 is a promising tool to review detailing provisions for integrity reinforcement.

Keywords: Punching shear; structural integrity; robustness; progressive collapse; flat slabs; accidental actions. 
1 Juan Sagaseta is a Lecturer at University of Surrey, Guildford, UK. He received his PhD from Imperial College

2 London, UK. His research interest include shear, punching shear, strut-and-tie modelling, analysis of structural 3 concrete under accidental actions and progressive collapse.

4 Nsikak W. Ulaeto is a PhD candidate at University of Surrey, Guildford, UK, where he also received his MSc. 5 His research interests include punching shear, post-punching, structural concrete under dynamic actions and 6 progressive collapse.

7 Justin Russell is a Research Fellow at University of Warwick, Coventry, UK. He received his PhD from 8 University of Nottingham, UK. His research interests include progressive collapse, concrete flat slabs and 9 dynamic analysis of FRP structures. 
2 Reinforced concrete flat slabs, especially the flat plate variation without drop panels and column capitals, are commonly used in infrastructure and the construction industry due to their efficient span-depth ratio and uniform soffit. The design of flat slabs at ultimate is mainly governed by the detailing of the slab-column connection in order to provide sufficient punching shear and deformation capacity. Punching is a brittle type of failure with almost no warning signs. The shear resistance at a column after punching can be very low unless special considerations are made in design to mitigate this effect (e.g. integrity reinforcement). Therefore, punching of a column can cause large redistribution of loads including an increase in shear and eccentricities (moment transfer) at the adjacent columns due to the irregular residual spans. These effects worsen due to the dynamic nature of the load redistribution leading to an amplification of the reactions and slab deflections from the global response.

Local failure at one column can propagate horizontally to adjacent columns in the slab as reported by Hawkins and Mitchell ${ }^{1}$ or Regan ${ }^{2}$; some examples of horizontal propagation collapses in underground car parking structures have been reported by Fernández Ruiz et $a l^{3}$. Horizontal propagation of failure can lead to the slab falling onto the floor below introducing large additional demands in the column-slab connections due to dynamic effects after the impact. This event can trigger the vertical progression of the collapse leading to a disproportionate collapse to the original cause. Examples of vertical collapses with severe economic and social consequences can be found in America (e.g. Skyline Plaza Complex in Virginia, USA, 1973), Asia (e.g. Sampoong Department Store, South Korea, 1995) and Europe (e.g. Bluche underground car parking, Switzerland, 1981). It is worth noting that there are also examples in which the vertical progressive collapse was successfully arrested by the slab leading only to partial collapse of the structure (e.g. Pipers Row car park in Wolverhampton, UK, 1997). This highlights the need to better understand the structural response of the system subjected to local failure in order to avoid introducing rules for design against progressive collapse that are unsafe or overly conservative.

The horizontal and vertical propagation of failure is highly dependent on the response of the column-slab connections in terms of their load and deformation capacity. This response is influenced by dynamic effects and the development of alternative load path mechanisms that could develop in the slab for small and large deformations such as compressive and tensile membrane action respectively. This paper analyses these relevant factors by means of simplified formulae based on theoretically sounded approaches used for punching and alternative load path analysis. A key aspect considered in this work is the use of load-deformation based formulae for punching which allow using energy balance principles to estimate the peak dynamic deformation. In this context, the Critical Shear Crack Theory (CSCT) by Muttoni ${ }^{4-5}$ is used and extended to dynamic cases of column removal situations which could be used in an alternative load path analysis for the design for structural robustness. For the alternative load path approach, the Ductility-Centred Robustness Assessment (DRA) developed by Izzudin $e t$ al. $^{6-8}$ was adopted; this approach, which was originally derived for the assessment of progressive collapse of multi-storey buildings, has been widely recognized and applied to real steel-framed composite multi-storey buildings ${ }^{8}$ and more recently to flat slab concrete buildings ${ }^{9}$. This paper shows that simple design formulae can be derived to assess punching at the adjacent connections after sudden column removal in flat slab concrete buildings (Fig. 1(a)) based on the DRA and CSCT approaches. A case study is shown of a real office building which has been previously analyzed by the authors (Olmati et al. ${ }^{10}$ ) using a more complex dynamic nonlinear finite element time history analysis. The role of membrane action (compressive and tensile) and post-punching response of the connection is also discussed based on analytical and numerical modelling carried out in this work which has been validated using existing experimental data of isolated slab tests.

\section{DESIGN AGAINST PROGRESSIVE COLLAPSE}

Structural robustness or integrity is commonly defined as the insensitivity of a structure to local failure. Understanding the causes of progressive collapse in building structures is essential towards the development of design methods for the assessment and improvement of structural robustness. The UK Building Regulations ${ }^{11-12}$ pioneered the inclusion of specific requirements against disproportionate collapse in codes of practice after the Ronan Point collapse in 1968. These general regulations were refined and used to feed into material-specific design codes; for concrete structures these were covered by BS $8110^{13}$ in the UK and subsequently passed on to some extent to Eurocode $2^{14}$ in Europe. In the US, the design against progressive collapse is currently covered by GSA ${ }^{15}$ and $\mathrm{DoD}^{16}$ guidelines and in less extent by ACI $318^{17}$ (section 7.13 and 13.3.8.5 for two-way slabs). An extensive review in this field by Arup ${ }^{18}$ showed that there are four recognized methods to design for structural robustness in general structures: (i) tying force provisions, (ii) alternative load path methods, (iii) key element design and (iv) risk-based methods. 
Tying force provisions are generally recommended for structures with low-risk of progressive collapse. Eurocode $2^{14}$ (section 9.10) defines a set of prescriptive detailing rules for those structures which are not specifically designed to withstand accidental actions which aim at providing a suitable "tying system" as shown in Fig. 1(c). Similarly, ACI 318 provides structural integrity requirements for detailing which is only intended to provide "improved redundancy and ductility" 17 . According to Eurocode 2, the objective of the tying system is to provide "alternative load paths" " after local damage by means of different mechanisms. However, it has been questioned over the years ${ }^{7,18-19}$ on whether the structure can achieve sufficient deformations to develop these mechanisms as prescriptive rules do not explicitly check the ductility of neither the connections nor the system. Moreover, the tying force requirements in Eurocode 2 were originally conceived for precast panel construction under blast or extreme wind conditions, similar to that in the Ronan Point collapse, and it is questionable whether these rules are directly applicable to other types of construction such as flat slabs under progressive collapse conditions. Flat slabs provide enhanced continuity and alternative load paths due to two-way bending and membrane actions ${ }^{20-22}$, however, they are prone to punching at small slab deflections. In this paper, it is shown analytically that punching would occur prior to the formation of the tensile membrane action (TMA) required by the tying system.
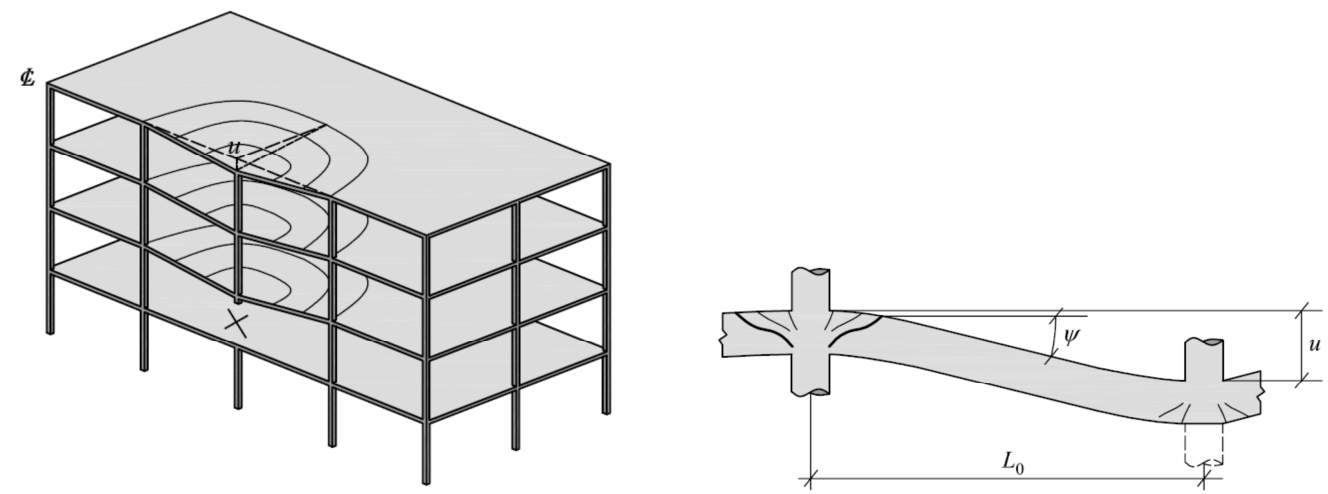

(b)

(c)

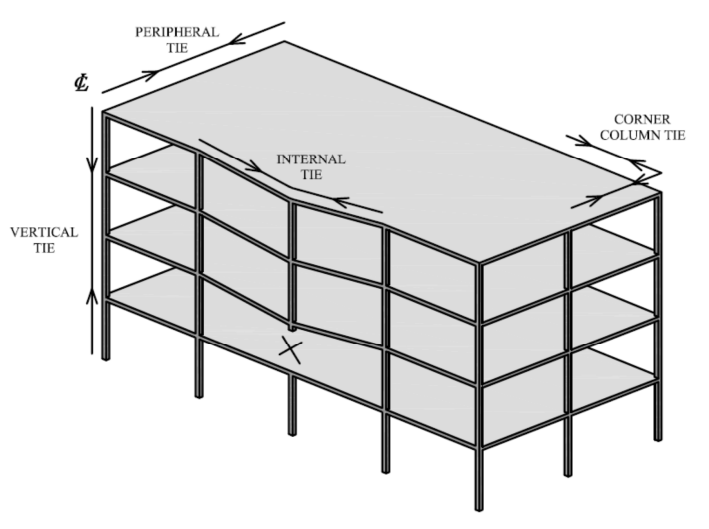

Figure 1 - Internal column removal scenario in concrete flat slab building: (a) SDOF approximation, (b) compatibility condition between vertical displacement and slab rotation and (c) tying approach.

Increasingly popular are the alternative load path methods ${ }^{6,15-16}$ for considering progressive collapse which offer a quantitative and more performance-based type of analysis although several simplifications are generally required. For example, scenario-independent approaches may be adopted (the hazard triggering local failure is not considered) which requires caution as key factors can be overlooked. In flat slab construction, some examples in which scenario-dependent approaches might need to be considered include fire or blast situations due to the continuity and redundancy of the structure (e.g. uplift pressures in blast or restraint strains after thermal gradients under high-temperature conditions). Otherwise, sudden column removal (scenarioindependent) is a widely accepted approach ${ }^{15-16}$ which provides a standard dynamic test of structural robustness which can cover different extreme events. There is a noticeable growing tendency in research and practice to focus on energy based approaches as described by Izzudin et al. ${ }^{7}$ which look at the deformation energy (strain energy) done by the external forces and can be also analysed as the flux of energy during the collapse $\left(\right.$ Szyniszewski et al. $^{23}$ ). 
A limitation of the application of the alternative load path approach in concrete flat slab design is the general lack of knowledge of the dynamic response (load and deformation capacity) of the column-slab connections. Design formulae for punching shear have traditionally focused on load capacity only and therefore they can only be used in load-centered alternative load path methods such as the simplified static modelling proposed by $\mathrm{DoD}^{16}$. The main drawback in such methods is the need to define load dynamic amplification factors $\left(\lambda_{\mathrm{d}}\right)$ which is cumbersome ${ }^{7}$. A value of $\lambda_{\mathrm{d}}$ equal to 2 is normally adopted in design for concrete structures ${ }^{15-16}$ which corresponds to a linear response without damping and therefore it provides overly conservative results. Test results on concrete flat slabs by Qian et al. ${ }^{21}$, Russell et al. ${ }^{22}$ and dynamic FE analysis by Liu and Olmati et al. ${ }^{10}$ show consistent values of $\lambda_{\mathrm{d}}$ between 1.2 and 1.6 depending on the gravity load and extent of the damage in the slab. The proposed simplified approach presented in this paper for assessing punching of adjacent columns under column removal situations provides consistent values of $\lambda_{\mathrm{d}}$ to those described in the literature $\mathrm{e}^{9-10,22}$.

If alternative load path analyses fail to demonstrate suitable capacity for the redistribution of loads, risk-based methods and/or the key element design method can be adopted. In the UK, for buildings above fifteen-story and/or of large occupancy (Class 3 buildings ${ }^{12}$ ), a systematic risk assessment is required which might include the design of specific key elements or alternative load paths. The design of key elements (removal of which will lead to the collapse) could be based on prescriptive loads such as ${ }^{12}$ or based on actual loads from hazard-specific guidelines (e.g. DoD ${ }^{16}$ ). Significant work is being carried out currently on risk-based approaches as recognized in a recent COST project ${ }^{24}$ and more emphasis is being made on probability-based approaches in which the uncertainty of basic parameters is included in the analysis. For instance, a simplified reliability analysis was proposed by Olmati et al. ${ }^{10}$ in which the magnitude of the gravity applied load is considered as a stochastic variable; this is a relevant parameter affecting the dynamic response of the flat slab structure as discussed in the following sections.

\section{RESPONSE OF FLAT SLAB BUILDINGS UNDER ACCIDENTAL ACTIONS}

Extreme events such as industrial accidents (e.g. vehicle impact, blast), unexpected local failure due to overloading or poor design, extreme weather or fire can lead to significant local damage. Such damage can include column failure, flexural failure of the slab, punching of the slab-column connection and spalling of concrete. The latter can be relevant as the size of debris and impact in other areas in the structure might be significant and could trigger progressive collapse due to overloading. It is worth noting that most of these events have a strong dynamic component; even local shear failures from a non-dynamic source (e.g. punching around a connection due to quasi-static loading) triggers a dynamic redistribution of loading due to the sudden loss of strength. Most codes acknowledge that the design against all possible accidental scenarios is not feasible since extreme events are normally unforeseen events and engineering judgement should prevail. However, the lack of theoretical models looking at the local and global response makes it difficult for the designer to tackle some of these issues.

\section{Local vs. global response}

The study of local damage is normally carried out for single structural elements as shown schematically in Fig. 2(a) for localized punching of a flat slab due to close-in detonation and impact. Analytical models exist to assess local perforation in such cases which can be based on SDOF models and the CSCT for punching (e.g. Micallef et $a ._{.}{ }^{25}$ and Sagaseta et $a l .{ }^{26}$ for impact and blast cases respectively). Work by Micallef et al. ${ }^{25}$ showed that the punching capacity increases with strain-rates as shown in Fig. 2(c) due to the increase in material strength with loading rate (increased residual tensile strength and aggregate interlock action along the critical shear crack). In cases of impulsive behavior as those shown in Fig. 2(a), punching may occur at a short time after the action, while the deformations are small compared to the peak deflection. The global response of the slab in such cases has been shown to have a negligible effect on the occurrence of punching which is primarily governed by the large shear demand around the localized action ${ }^{25-26}$. Due to the continuity and monolithic nature of flat slab systems, the interaction between local and global response is not straightforward and the development of hybrid models (local-global) is useful for different types of loading with different load durations. 

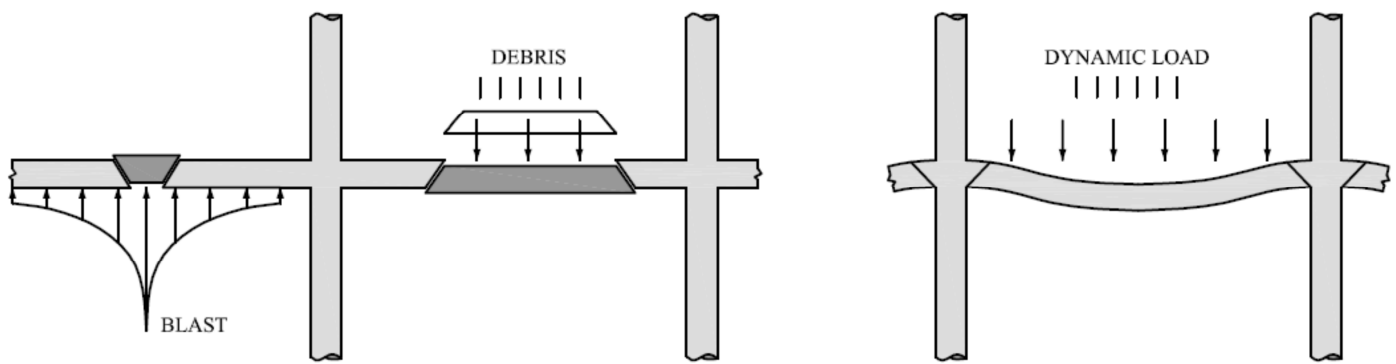

(a)

(b)

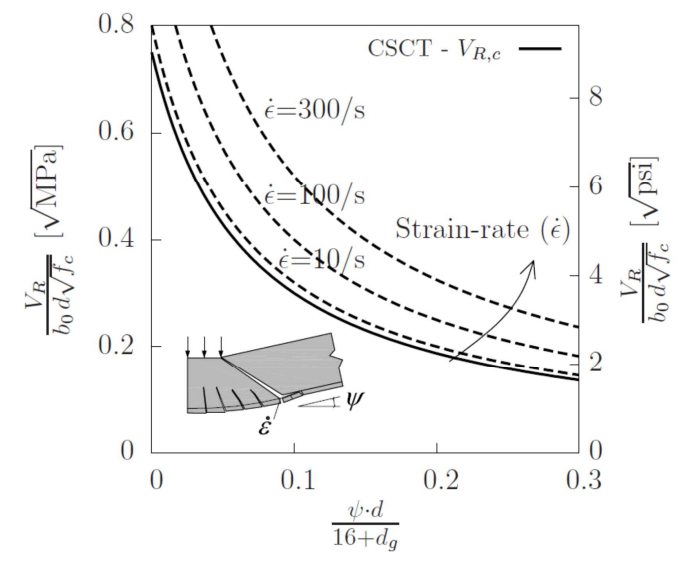

Figure 2 - Local vs. global response: (a) punching of the slab during local impulsive behavior, (b) punching of the column-slab connection at peak dynamic response and (c) influence of slab rotation and strain-rate on punching strength according to $\mathrm{CSCT}^{4}$ and Micallef et al. ${ }^{25}$.

In cases where local failure is not critical, the dynamic loads in the slab are amplified and transferred to the column-slab connections (dynamic reactions) by means of the global dynamic response as shown schematically in Fig. 2 (b). In this case, the maximum reactions take place at the time of maximum peak deflections (i.e. maximum resistance in the flexural response). The magnitude of the gravity loads applied in the slab (dead $D+$ live $L$ loads) is relevant as it influences the response of the system which in turn affects the response of the connections ${ }^{10,22}$. As discussed by Russell et al. ${ }^{22}$, the increase in gravity loads affects the response of the system due to (a) changes in the natural frequency due to mass changes and (b) increase in damage to the structure which reduces the stiffness and natural frequency leading to an increase of the peak response.

Punching in both local and global situations can be examined using the $\operatorname{CSCT}^{4-5}$ which considers that the punching capacity reduces with increasing slab rotation $\psi$ as shown in Fig. 2(c) (strain effect on punching shear). The slab rotation $\psi$ is measured outside the critical shear crack as shown in Fig. 1(b) and 2(c). In local dynamic punching of the slab, failure occurs when the capacity is large (i.e. low rotations) whereas in cases of punching around column-slab connections, shear failure might occur at the moment of lowest capacity (i.e. large rotations during peak deflections). The shear demand in both situations can be extremely large and therefore punching could take place prior reaching the maximum global deformations. The simplified approach presented in this paper for the column-slab connections considers the dynamic effects described above.

It is worth noting that whilst the proposed approach in this paper is relevant towards assessing structural robustness, the occurrence of local punching might not necessarily imply the development of progressive collapse which should be assessed on a system-based analysis considering punching and post-punching mechanisms. The non-linear response of the slab can activate different mechanisms ${ }^{27}$ including flexure, compressive membrane action (CMA) and tensile membrane action (TMA) as shown in Fig. 3. These mechanisms have been traditionally investigated separately and their interaction with punching is not well known. Punching at the connections is observed in regions 2 and 3 (Fig. 3) in which CMA and flexure are predominant; the snap-through behavior in region 4 is followed by full catenary action which could potentially develop after punching. Punching shear models based on deformations (e.g. CSCT) have the potential to capture the transition between these four regions shown in Fig. 3 as discussed further in this paper. 


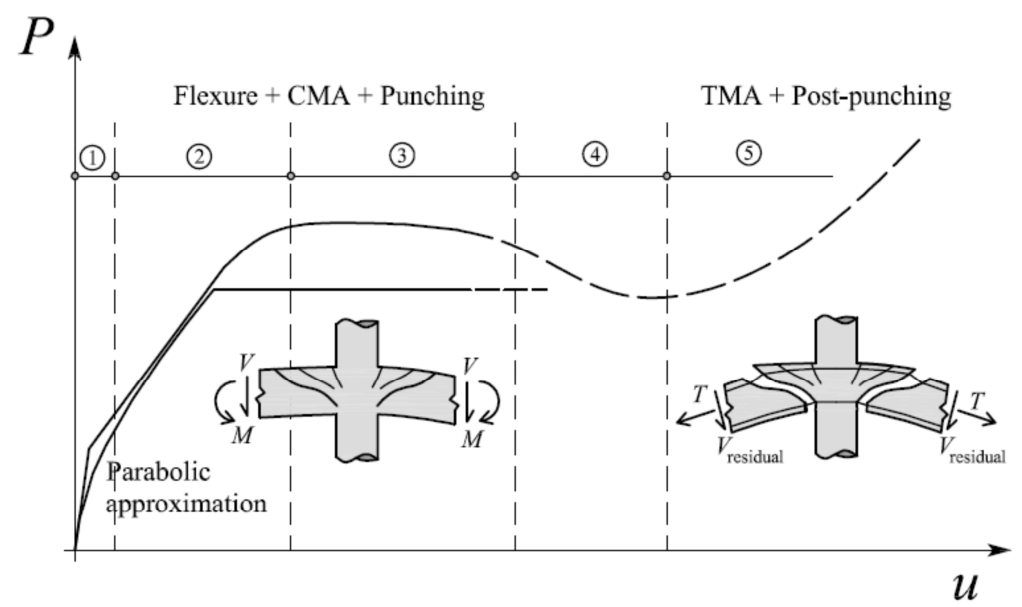

Figure 3 - Structural response of flat slab structures (adapted from Mitchell and Cook $^{27}$ ). ASSESSMENT OF PUNCHING OF ADJACENT COLUMNS AFTER COLUMN REMOVAL

\section{Idealization of column damage}

The sudden column removal scenario as proposed in codes of practice ${ }^{15-16}$ is probably the most common type of design situation considered in the assessment of structural robustness. This approach studies the indirect response of the building subject to an idealized theoretical structural damage with focus on the ability of the structure to find alternative load paths. In this scenario, the selected support is removed instantaneously which provides an upper bound in terms of the dynamic response. Whilst the concept and purpose behind this approach is clear, the approach is not meant to cover all accidental actions as recognized by $\mathrm{DoD}^{16}$ since the nature of the load causing the failure of the column is not considered. As reported by ${ }^{18}$ there is scarce information in the literature regarding whether this is a realistic or overly conservative approach. The sudden column removal neglects any residual strength and stiffness of the column after local failure, which is clearly not the case for instance when the triggering event (local failure) is punching at the support as shown by testing on postpunching ${ }^{3,28-29}$. As shown by Keyvani et al. $^{30}$, even in demolition tests in a post-tensioned flat slab building in which a column was exploded intentionally to remove it completely, some residual resistance was observed at the column due to residual deformations and some reinforcement bars surviving the explosion.

\section{Demand-capacity ratio of adjacent column after sudden column removal}

The assessment of punching of adjacent columns after sudden column removal is challenging due to the uncertainty in the magnitude and role of the main parameters involved. Equation (1) shows the main factors affecting the demand-capacity ratio $(D R)$ of the adjacent column after this event $(D R>1$ meaning that punching will occur). The contribution of each parameter is described in this section.

$$
D R=D R_{0}\left(\Delta_{\mathrm{V}} \lambda_{\mathrm{d}}\right) \Delta_{\mathrm{M}} \Delta_{\mathrm{S}}
$$

Parameter $D R_{0}$ is the demand-capacity ratio of the connection being investigated for a specified loading prior to the removal of an adjacent column, $\Delta_{\mathrm{V}}$ is the increase ratio of static shear force at the adjacent column after the column removal, $\lambda_{\mathrm{d}}$ is the dynamic load amplification factor, $\Delta_{\mathrm{M}}$ is the increase ratio of shear demand due to moment transfer increase and $\Delta_{\mathrm{S}}$ is the decrease ratio of punching capacity due to the increase in span length (i.e. increased slenderness). $D R_{0}$ is influenced by the gravity load considered and the design punching capacity of the connection $\left(V_{\mathrm{Rd}}\right)$ considering nominal sizes of rebar and number of effective shear reinforcement provided around the column. Regarding the gravity loads, in this work Eurocode $0^{31}$ is used which gives combination of actions for accidental loading which includes the quasi-permanent $(\mathrm{D}+0.3 \mathrm{~L})$ and frequent (D+0.5L) combination cases in buildings with load categories A (domestic, residential) and B (office areas).

In terms of static behavior, it is widely assumed that in slabs with equal spans in both directions, the load carried out by the removed column is transferred equally to the four closest adjacent columns leading to an increase in the total shear at the adjacent columns of $25 \%$ (i.e. $\Delta_{V}=1.25$ ). A linear finite element analysis (LFEA) of a flat slab with infinite number of spans on either side and $L_{\mathrm{y}} / L_{\mathrm{x}}=1$ (column size to effective depth $c / d$ between 0.5 and 2 and column size to span $c / L$ between 0.025 and 0.1 ) shows that $\Delta_{V}$ can vary between 1.33 and 1.35 (Fig. 4(a)) which is due to the unbalanced load and unloading of the second row of columns (slab continuity). The 
corner column adjacent to the removed one does not contribute significantly to this redistribution; the contour diagrams in Fig. 4(a) show that the deformations around this column are similar to columns two spans from the removed one. Parameter $\Delta_{\mathrm{V}}$ can increase significantly in buildings with irregular distribution of columns. For instance if the span length in one direction is significantly shorter than in the other direction (e.g. $L_{\mathrm{y}} / L_{\mathrm{x}}>1.5$ ) then the load carried out by the removed column can be transferred almost entirely to the closest columns (i.e. $\Delta_{V} \approx 1.5$ ) as shown in Fig 4(a). In slabs with irregular bays with columns with different contributable areas, the removal of highly demanded columns can result in values of $\Delta_{\mathrm{V}}$ closer to 2 as shown by Olmati et al. ${ }^{10}$. Moreover, the increase in total shear in the column will be amplified due to dynamic effects by a factor $\lambda_{\mathrm{d}}$ which could vary depending on the gravity loads and column distribution.

(a)

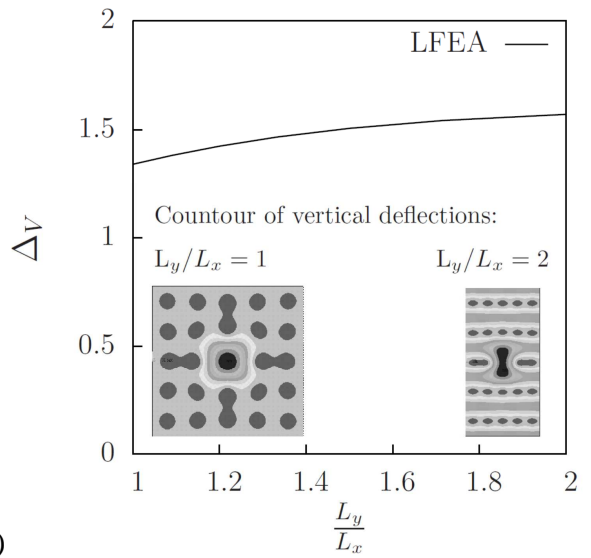

(b)

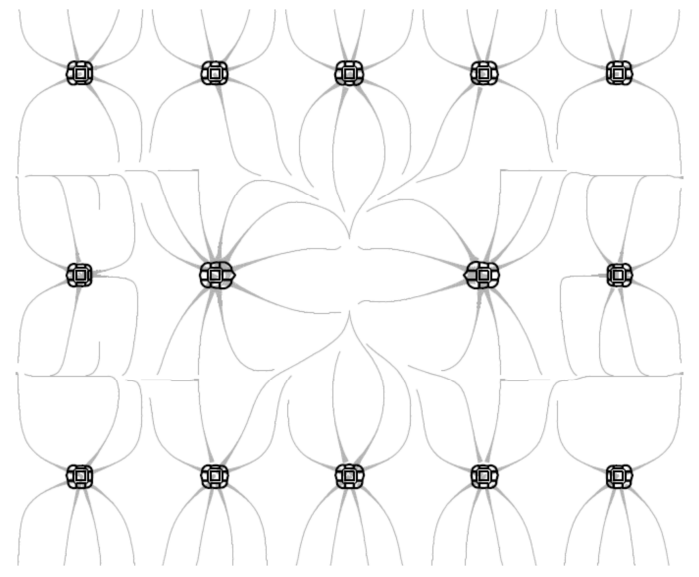

Figure 4 - Influence of column removal on: (a) static reaction in rectangular column layouts (contour diagrams indicate the deflections in the slab for different cases of $L_{y} / L_{x}$ ) and (b) distribution of shear forces along control perimeter at $0.5 d$ from column face for $L_{\mathrm{y}} / L_{\mathrm{x}}=1.5$ according to shear field analysis.

Column removal results in an increase in the moment transfer in the adjacent columns which in turn will cause a high concentration of shear forces in the control perimeter at the side of the removed column as shown in Fig. 4(b) obtained from a shear field analysis (thin lines represent the flow of principal directions of the shear stress vectors and thick lines represent the magnitude of the shear per unit length along the control perimeter at $0.5 d$ from the columm face). Moment transfer is considered in design codes as an increase in shear stress demand by means of increase factors based on a given shear distribution (Eurocode 2, ACI 318). Alternatively, other codes such as Model Code 2010 use a reduced length of the control perimeter also known as "shear resisting control perimeter" by means of a reduction factor $k_{e}$. Therefore, parameter $\Delta_{\mathrm{M}}$ can be easily obtained using existing design formulae in the different $\operatorname{codes}^{5,14,17}$. It is worth noting that due to the irregular residual spans, recommended constant values for these factors normally do not apply and formulae based on obtained eccentricities need to be used in such cases. Dynamic effects are likely to influence $\Delta_{\mathrm{M}}$ although the variations observed in the shear stress demand factors are small with respect to those obtained from a static analysis with residual spans (Olmati et al. ${ }^{10}$ ).

The influence of slenderness on punching has been investigated by Einpaul et al. ${ }^{32}$ showing that an increase of slenderness in isolated tests leads to a decrease in stiffness of the load-rotation response of the slab and hence a reduction of the punching capacity due to larger crack widths. This reduction in punching capacity $\Delta_{\mathrm{S}}$ is more significant for slabs with shear reinforcement ${ }^{32}$ and it is currently not considered in Eurocode 2 and ACI 318 provisions. In a regular orthogonal column distribution, the slenderness of the critical span will double after the loss of one column. Assuming a common office building in the UK with a slenderness $(0.22 L) / d$ of around 5 , the column removal will result in a punching capacity reduction according to the CSCT of around $20 \%\left(\Delta_{\mathrm{S}}=\right.$ 0.80 ) for a connection with shear reinforcement and heavily reinforced in flexure (e.g. $\rho=1.5 \%$ ) and as low as $10 \%\left(\Delta_{S}=0.9\right)$ if the connection has no shear reinforcement. In addition, dynamic amplification of the deflections will result in a further reduction of the punching capacity due to wider cracks. As shown in next section, this dynamic effect could be captured using the CSCT with an increased equivalent static slenderness or "pseudo-static slenderness". This is a similar analogy but opposite to that observed in local punching in impulsive cases of impact and blast in which the small flexural deformations at punching could be viewed as a "reduced effective slenderness" which is also referred to by in the literature ${ }^{25,33}$ as "reduced span". 
In this paper it is shown that for quasi-static column removal, the effect of increased slenderness on the flexural response due to the increase in span lengths is captured accurately using Model Code 2010 formulae ${ }^{5}$. The example shown in Fig. 5 (a) and (b) corresponds to a four-story office building described in Technical Report $64^{34}$ which is commonly referred to in flat slab design in the UK. Equation (2) is proposed in this work which is based on the load-rotation relationship given by ${ }^{5}$ (Level of Approximation LoAII), considering the increase in slenderness after the column removal at a shear force equal to $V_{0}$. Figure 5(c) shows that the predictions from Eq. (2) are comparable with those obtained from a nonlinear finite element analysis (NLFEA) with quasi-static loading by Olmati et al. ${ }^{10}$. Figure 5(c) also shows that the sudden change in slope in the load-rotation curve (Eq. (2)) after column removal is captured correctly by increasing the slenderness from $r_{\mathrm{s} 0} / d=0.22 L_{0} / d$ to $r_{\mathrm{s} 1} / d=0.22 L_{1} / d$ where $r_{\mathrm{s}}$ is the approximate distance from the support axis to the point of zero radial bending moment (subscripts 0 and 1 denote before and after column removal respectively) and $L_{0}$ and $L_{1}$ are the length of the original and residual span respectively $\left(L_{0}=6 \mathrm{~m}[19.7 \mathrm{ft}]\right.$ and $L_{1}=12 \mathrm{~m}$ [39 ft] for the case considered).

$$
\psi=1.5\left(\frac{r_{\mathrm{s} 1}}{d}\right)\left(\frac{f_{\mathrm{y}}}{E_{\mathrm{s}}}\right)\left(\frac{V-0.37 V_{0}}{k m_{\mathrm{R}}}\right), \forall V>V_{0}
$$

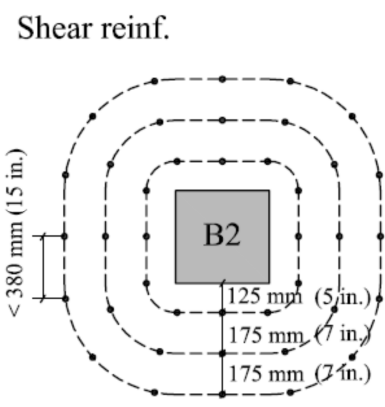

(b) where according to Model Code $2010^{5}, k=8\left(2 b_{\mathrm{s}}\right) /\left(2 b_{\mathrm{s}}+8\left|e_{\mathrm{u}, \mathrm{i}}\right|\right)$ and $b_{\mathrm{s}}$ is the width of the support strip (normally equal to $1.5 r_{\mathrm{s}}$ for internal columns with regular span layout) and $e_{\mathrm{u}, \mathrm{i}}$ is the eccentricity of the resultant of the shear forces with respect to the centroid of the basic control perimeter in the direction investigated (direction of residual span). For shear forces $V$ lower than $V_{0}$, Eq.(2) still applies by replacing terms $\left(r_{\mathrm{s} 1} / d\right)$ and $\left(V-0.37 V_{0}\right)$ by $\left(r_{\mathrm{s} 0} / d\right)$ and $V$ respectively. A more refined analysis (LoAIII $\left.{ }^{5}\right)$ was carried out using a LFEA showing very small differences in the values adopted for $r_{\mathrm{s}}$ and $k$; in particular, parameter $k$ was close to 8 using LoAII and III for the eccentricities obtained in the case study shown in Fig. 5.

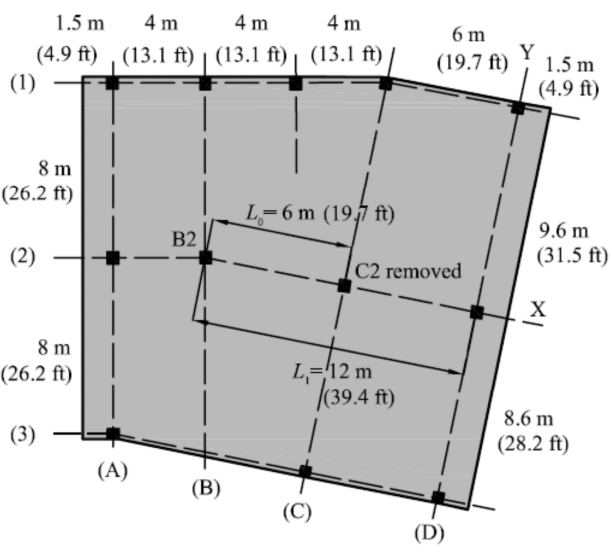

(a)

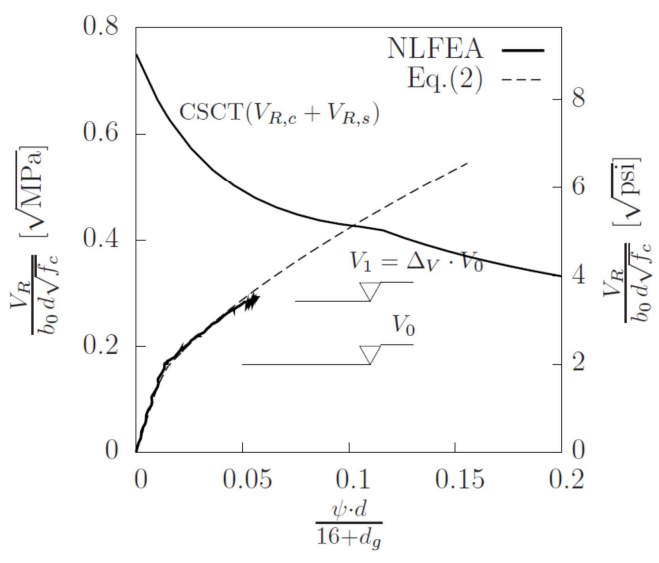

Figure 5 - Non-linear static response of column B2 after removal of column C2: (a) plan view of flat slab structure, (b) shear reinforcement at B2 and (c) load-rotation response Eq.(2) and quasi-static NLFEA ${ }^{10}$. 
Evaluating Eq.(1) using plausible values in design shows that $D R$ can easily reach values near 0.8 for frequent load combinations (D+0.5L). For example, the case study investigated by Olmati et al. ${ }^{10}$ (Fig. 5), for the load combination (D+0.5L) resulted in the following: $D R_{0}=0.3, \Delta_{\mathrm{V}}=1.7, \Delta_{\mathrm{M}}=1.15$ and $\Delta_{\mathrm{S}}=0.85$ which gives $D R=0.5 \lambda_{\mathrm{d}}$; assuming a conservative dynamic factor of 2 will result on imminent punching $(D R=1.0)$ whereas assuming more realistic values of $\lambda_{\mathrm{d}}$ (e.g. $\lambda_{\mathrm{d}}=1.3$ from a refined dynamic analysis ${ }^{10}$ ) shows that punching is not predicted to occur. This justifies the use of dynamic analysis to assess $\lambda_{\mathrm{d}}$ and $\Delta_{\mathrm{S}}$ in a more rigorous and systematic manner. A dynamic nonlinear analysis is considered the most theoretically rigorous and refined method to address this problem, however this approach is highly complex and computationally demanding. A simplified approach is presented in the following section based on a nonlinear static pushover analysis and simplified dynamic response based on energy balance as proposed by Izzudin et al. ${ }^{6-8}$.

Application of the Ductility-Centred Robustness Assessment (DRA):

The DRA proposed by Izzudin et al. ${ }^{6-8}$ is applied to flat slab structures in this work. This approach can be applied to different levels of structural idealization. For instance, Liu ${ }^{9}$ used DRA and CSCT in their analysis of a concrete flat slab building system by means of a macro numerical model. In this paper, the focus is on the isolated response of the column-slab connection (sub-system) until punching failure; simplified analytical equations are derived for this particular case.

As reported by Izzudin and Nethercot ${ }^{7}$ ductility-centered approaches such as the DRA allow consideration of three critical factors for structural robustness namely, energy absorption capacity, redundancy and ductility supply. Moreover this approach proposes the system pseudo-static capacity as a single measure of structural robustness. The DRA consists of three steps: (i) determination of the nonlinear static response of the system considered, (ii) dynamic assessment using a simplified approach based on energy balance and (iii) ductility assessment of the connections by means of compatibility conditions between the system and the sub-system. In this case, the flat slab system represents the bay of the removed column and the adjacent columns with the floors above; this system can be modelled as a single degree of freedom SDOF system consisting of the vertical deflection at the point of the removed column $u$ as shown in Fig. 1(a).

The static response of the flat slab system is clearly nonlinear due to cracking of the concrete and yielding of the reinforcement in the slab in the hogging and sagging regions (Fig. 3). Load-rotation relationship (Eq.2) can be adopted in which the reactions and hence the gravity load is proportional to $\psi^{2 / 3}$ where $\psi$ is the slab rotation in the direction of the longest span outside the column region. The rotation of the slab varies along the span, from zero at the column to a maximum value right outside the column region and then it remains constant and gradually reduces to zero at mid-span. The exact distribution of slab rotation will vary depending on the loading and amount of hogging and sagging reinforcement in the column and mid-span regions respectively due to moment redistribution ${ }^{35}$. The compatibility condition between the system and sub-system degrees of freedom is in this case simple to use $u \approx 1.5 L_{0} \psi$ (Fig. 2(b)) which has been verified by the authors against experimental and numerical results of continuous slabs with different hogging and sagging reinforcement ratios ${ }^{35}$. It is worth noting that the value of the constant of proportionality of this relationship is not relevant in the dynamic study. It can be concluded that the nonlinear static response of the system until punching will follow a parabolic relationship $P \propto u^{2 / 3}$ as shown in Fig. 3. The linear elastic response (region 1 in Fig. 3) is neglected as commonly assumed in punching assessments in quasi-static loading; the loads causing punching normally result in cracking and crushing of the concrete whilst yielding of the flexural reinforcement. This assumption holds true for dynamic punching in column-slab connections governed by the global response of the structure.

The second step according to the DRA involves an energy balance calculation in order to obtain the peak dynamic vertical deflection of the system $\left(u_{\text {dyn }}\right)$. The total gravity load applied in the system $(P)$ after the column removal can be divided into two components, one is a static component which is resisted by the static reactions after the column removal $\left(V_{1}\right)$ and the other component is dynamic which is equal to the reaction of the column removed which is applied suddenly into the system. As shown by Izzudin et al. ${ }^{7}$, the application of a sudden load will introduce an amplification of the deflections so that the maximum dynamic response is obtained when the kinetic energy of the system is zero and therefore the external work introduced by the gravity loads equals the internal energy absorbed by the system. For instance, in a linear system shown in Fig. 6(a), if the load $P_{\text {stat }}$ is applied gradually the system will deflect $u$ (external work introduced = internal strain energy absorbed) whereas if the same load was applied suddenly the deflection would need to be $u_{\mathrm{dyn}}=\lambda_{\mathrm{u}} u=2 u$ to balance external work and internal energy $\left(\lambda_{\mathrm{u}}\right.$ is the dynamic deflection amplification factor). If the system follows a parabolic relationship $P \propto u^{2 / 3}$, it can be easily demonstrated that the deflection would need to be $u_{\text {dyn }}=\lambda_{\mathrm{u}} u=2.15 u$. If the system follows a parabolic-plastic behavior as shown in Fig. 6(b), with a limit value $P_{\text {lim }}$, factor $\lambda_{\mathrm{u}}$ will be constant and equal to 2.15 for static gravity loads lower than $P_{\text {lim,ps }}$ (e.g. load $P_{\text {stat }, 1}$ ) 
whereas for static gravity loads higher than $P_{\text {lim,ps }}$ (e.g. load $\left.P_{\text {stat,2 }}\right) \lambda_{\mathrm{u}}$ will increase significantly in order to achieve balance between internal strain energy and external work (shaded areas in Fig.6(b)). In Fig.6(b), $P_{\text {lim,ps }}$ is the static gravity load giving a dynamic deflection $u_{\mathrm{dyn}}$ which is equal to $u_{\mathrm{lim}}$, where $u_{\mathrm{lim}}$ is the value of the deflection in the static response at which $P_{\text {lim }}$ is reached. The applied load versus maximum displacement obtained from the energy balance approach is defined by Izzudin et al. ${ }^{7}$ as the "pseudo-static response" as it can be obtained using static analysis. Figure 6(b) shows that for a given static gravity load $P_{\text {stat }}$, the peak deflection can be obtained from the pseudo-static response and the corresponding amplified dynamic load $\left(P_{\mathrm{dyn}}=\right.$ $\left.\lambda_{\mathrm{d}} P_{\text {stat }}\right)$, can be obtained from the nonlinear static response.

The pseudo-static response $\left(P_{\text {stat }}, u_{\text {dyn }}\right)$ can be written in terms of the static shear force around the column and pseudo-static rotation $\left(V, \psi_{\mathrm{ps}}\right)$ as shown in Eq. (3). Equation (3) was derived using the static response $(V, \psi)$ from Eq. (2) and applying the energy based principles by multiplying $\lambda_{\mathrm{u}}$ to the difference in slab rotation $\left(\psi-\psi_{0}\right)$ to obtain $\psi_{\mathrm{ps}}$ where $\psi_{0}$ is the slab rotation near the column investigated before the column removal. Equation (3) is used subsequently in the ductility assessment in the last step in the DRA approach.

$$
\psi_{\mathrm{ps}}=1.5\left(\lambda_{\mathrm{u}} \frac{r_{\mathrm{s} 1}}{d}\right)\left(\frac{f_{\mathrm{y}}}{E_{\mathrm{s}}}\right)\left[\left(\frac{V-0.37 V_{0}}{k m_{\mathrm{R}}}\right)^{3 / 2}-\frac{\left(\lambda_{\mathrm{u}}-1\right)}{2 \lambda_{\mathrm{u}}}\left(\frac{V_{0}}{k m_{\mathrm{R}}}\right)^{3 / 2}\right] \quad, \forall V>V_{0}
$$

where $\lambda_{\mathrm{u}}$ is the dynamic deflection amplification factor to the slab rotation near the column which is equal to 2.15 for $\psi_{\mathrm{ps}} \leq \psi_{\mathrm{lim}}$ where $\psi_{\mathrm{lim}}$ corresponds to the deflection $u_{\mathrm{lim}}$ shown in Fig. 6(b). In the plastic region $\left(\psi_{\mathrm{ps}}>\psi_{\mathrm{lim}}\right)$, factor $\lambda_{\mathrm{u}}$ is given by Eq.(4) which was also derived from energy balance (Fig. 6(b)):

$$
\lambda_{\mathrm{u}}=\frac{\psi_{\mathrm{ps}}^{5 / 3}}{\left[\psi_{\mathrm{ps}} \psi_{\mathrm{lim}}^{2 / 3}-0.4 \psi_{\mathrm{lim}}^{5 / 3}\right]^{3 / 2}} \quad, \forall \psi_{\mathrm{ps}}>\psi_{\mathrm{lim}}
$$

The pseudo-static response of the connection given by Eq.(3) follows a similar form to the static response except for the introduction of coefficient $\lambda_{\mathrm{u}}$ obtained from energy balance. In Eq.(3), term $\left(\lambda_{\mathrm{u}} r_{\mathrm{s} 1} / d\right)$ can be interpreted as an equivalent "pseudo-static slenderness" which accounts for dynamic amplification effects. The negative term in Eq.(3) accounts for the fact that the dynamic amplification takes place from the load-rotation point $\left(V_{0}, \psi_{0}\right)$.

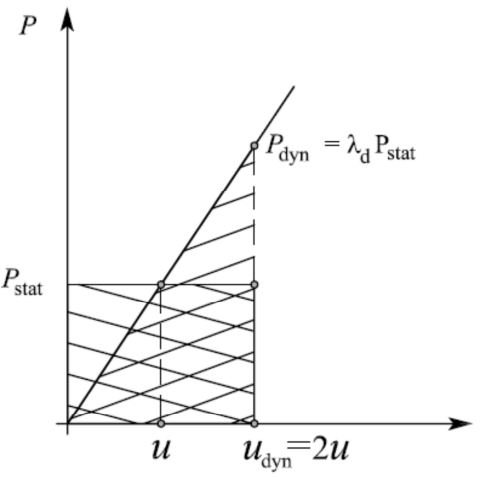

(a)

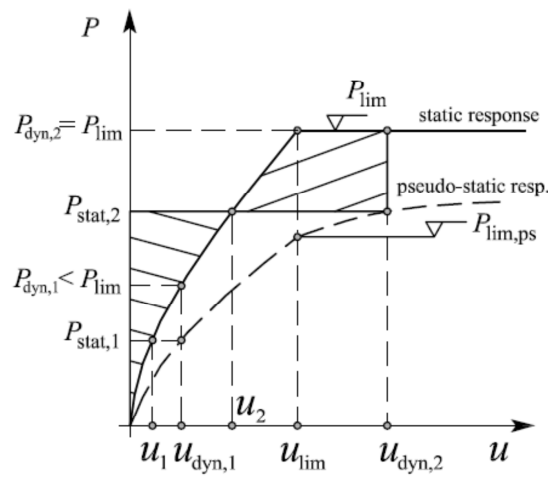

(b)

igure 6 - Pseudo-static response according to simplified dynamic assessment ${ }^{6}$ : (a) linear response and (b) parabolic-plastic response proposed in this work.

The dynamic amplification factor of the load $\left(\lambda_{\mathrm{d}}\right)$ can be obtained separately from the static and the corresponding pseudo-static response. For a linear system, this approach gives $\lambda_{d}=2$ as expected, whereas for a linear-plastic system this factor reduces significantly for loads near the plastic region. For the column-slab connections under investigation, Eq.(2) and (3) are used to calculate $\lambda_{\mathrm{d}}$ leading to Eq.(5) for loads below the plastic region

$$
\lambda_{\mathrm{d}}=0.37\left(\frac{V_{0}}{V}\right)+\left[\lambda_{\mathrm{u}}\left(1-0.37 \frac{V_{0}}{V}\right)^{3 / 2}-\frac{\left(\lambda_{\mathrm{u}}-1\right)}{2}\left(\frac{V_{0}}{V}\right)^{3 / 2}\right]^{2 / 3} \quad, V_{0}<V<V_{\lim } / \lambda_{\mathrm{d}}
$$

where $\lambda_{\mathrm{u}}$ is 2.15 for this region. For loads near the plastic region where $\lambda_{\mathrm{u}}$ increases significantly according to Eq.(4), the dynamic load factor is simply $\lambda_{\mathrm{d}}=V_{\text {lim }} / V$ which decreases tending to 1 for large rotations assuming 
that only flexural behavior is activated (i.e. without tensile membrane action). The reduction of $\lambda_{\mathrm{d}}$ for ductile systems has been recognized for some time and it has been considered by codes of practice ${ }^{16}$ for some types of construction. It is worth noting that the activation of tensile membrane action for large deformations would result in a sudden increase of $\lambda_{\mathrm{d}}$ (Izzudin and Nethercot ${ }^{7}$ ), however in flat slabs, punching of the connection would precede in such cases as shown in next section. The proposed Eq. (5) for punching gives values of $\lambda_{\mathrm{d}}$ between 1.67 and 1.2 depending on $V_{0} / V$ which is a function of the column distribution. These values are consistent with those obtained experimentally ${ }^{22}$ or numerically ${ }^{10}$ for flat slabs with similar levels of gravity loads. For cases of sudden corner column removal, Qian and $\mathrm{Li}^{20}$ reported values of $\lambda_{\mathrm{d}}$ between 1.13 and 1.23.

In order to carry out the ductility assessment in the third step of the DRA, the failure criterion in the CSCT is applied. The proposed method to assess punching shown in Fig. 7 is described as follows:

- For a given static gravity load $\left(P_{\text {stat }}\right)$, obtain the static shear before $\left(V_{0}\right)$ and after $\left(V_{1}\right)$ the column removal.

- Obtain the corresponding pseudo-static rotation $\psi_{p s}$ for $V=V_{1}$ from Eq.(3).

- For the obtained pseudo-static rotation, calculate the dynamic demand $V_{\text {dyn }}=\lambda_{\mathrm{d}} V_{1}$ from Eq.(5) or using the static response, and the dynamic capacity $V_{\mathrm{R}, \text { dyn }}$ from the CSCT failure criterion ${ }^{4-5}$.

- Check whether the demand is lower than the capacity $V_{\text {dyn }}<V_{\mathrm{R}, \text { dyn }}$, if so the procedure indicates there should not be punching of the adjacent column under consideration.

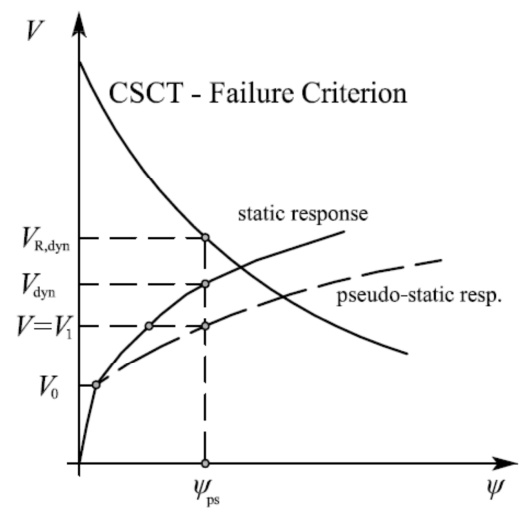

Figure 7 - Proposed approach for punching assessment of sudden column removal based on the CSCT and pseudo-static response from DRA.

As shown in Fig. 7 the philosophy behind the proposed approach is similar to punching for quasi-static loading due to the use of the pseudo-static relationship. The proposed method is simple and it allows to check both load and deformation capacity considering dynamic effects in a consistent manner. The dynamic factors are automatically considered and refined predictions of the static response can be obtained by increasing the LoA adopted. Strain-rate effects could be considered in the punching capacity and demand. For the punching shear capacity, refining the failure criterion as a function of the strain-rate is possible ${ }^{25}$ as shown in Fig.2(c). For the punching shear demand, a refined load-rotation response can be considered using material enhancement factors dependent on the strain-rate ${ }^{5}$ as shown by Liu 9 (FE model with shell elements) or SDOF models as shown by Micallef $e t a l .{ }^{25}$. Furthermore, the proposed approach neglects shear redistribution around the perimeter (only the radial direction along the residual span giving the maximum rotation is considered); as shown by Sagaseta $e t$ $a l .{ }^{36}$ if sufficient deformation capacity is provided in the direction of the maximum rotation more refined predictions can be obtained using the CSCT considering the load-rotation in both orthogonal directions. The simple proposed method and the different refinements described above can be written in a LoA format similar to that proposed in Model Code 2010 so that it could be easily be applied in practice at different design stages.

\section{Example of application of proposed method and comparison with dynamic NLFEA}

The proposed method was applied to the case study of the office building shown in Fig. 5 which was designed for flexure and punching according to Eurocode 2. This structure was previously analyzed by the authors ${ }^{10}$ using a more refined time history dynamic NLFEA for different gravity load combinations as part of a reliability study. The span layout and main geometry are summarized in Fig. 5(a) and (b). In the dynamic NLFEA, the gravity load was introduced gradually in the system and then column C2 was removed suddenly. Figure 8 shows that the dynamic NLFEA predicted that punching would not occur in the adjacent column B2 for the frequent load combination $(\mathrm{D}+0.5 \mathrm{~L})(D R=0.9)$ whereas punching was predicted to occur for the characteristic load combination $(\mathrm{D}+\mathrm{L})(D R=1.1)$ which demonstrates that the structure is acceptable for accidental loading according to Eurocode $0^{31}$. The dynamic NLFEA shown in Fig. 8 shows that after the sudden column removal, a slight unloading was predicted followed by a large amplification of the load and deformations following roughly 
the nonlinear static response given by Eq.(2). As shown in Fig. 8, after reaching the peak deflections the structure goes into the free vibration phase around a shear force equal to the static value $\left(V_{1}\right)$ as expected.

Figure 8 shows that the proposed approach gives similar predictions of punching to the dynamic NLFEA with $V_{\text {dyn }}<V_{\mathrm{R} \text {,dyn }}$ (no punching) in the frequent load combination (Fig. 8(a)) and $V_{\text {dyn }} \approx V_{\mathrm{R}, \text { dyn }}$ (punching) in the characteristic load combination (Fig. 8(b)). The dynamic amplification factor of the load $\lambda_{\mathrm{d}}$ obtained according to Eq. (5) for the frequent combination $\left(V_{0}=508 \mathrm{kN}\right.$ [114 kip] and $V_{1}=833 \mathrm{kN}$ [187 kip]) was equal to 1.35 compared to 1.36 from the dynamic NLFEA ${ }^{10}$. For the frequent load combination $\left(V_{1}\right)$, the ratio between the maximum dynamic rotation and the static one (including rotation $\psi_{0}$ ) is 1.76 compared to 1.80 obtained from the dynamic NLFEA. The maximum vertical deflection of the system $u_{\text {dyn }}$ predicted by the NLFEA had a dynamic amplification factor of 1.82 after the column removal which is reasonably similar to the one derived in this work from energy balance $\left(\lambda_{\mathrm{u}}=2.15\right)$. Some differences between the results from the dynamic NLFEA and the proposed method are expected as the latter approach does not take into account damping. The dynamic amplification factors obtained in this work are also consistent to those obtained by Liu ${ }^{9}$ for a different prototype building designed according to ACI 318 (4 span building with orthogonal column grid with $L_{\mathrm{x}}=L_{\mathrm{y}}=6 \mathrm{~m}$ [20ft]); in their analysis $\lambda_{\mathrm{u}}$ obtained from their macro-model was 2.10 instead of 2.15 and $\lambda_{\mathrm{d}}$ was 1.35 whereas in this work a value of 1.25 is obtained using Eq.(5) for the column distribution considered $V_{1} / V_{0}=1.3$ ).

(a)

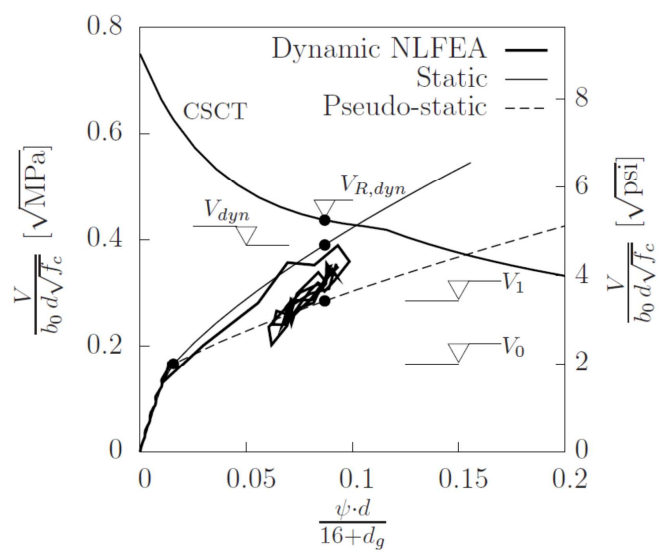

(b)

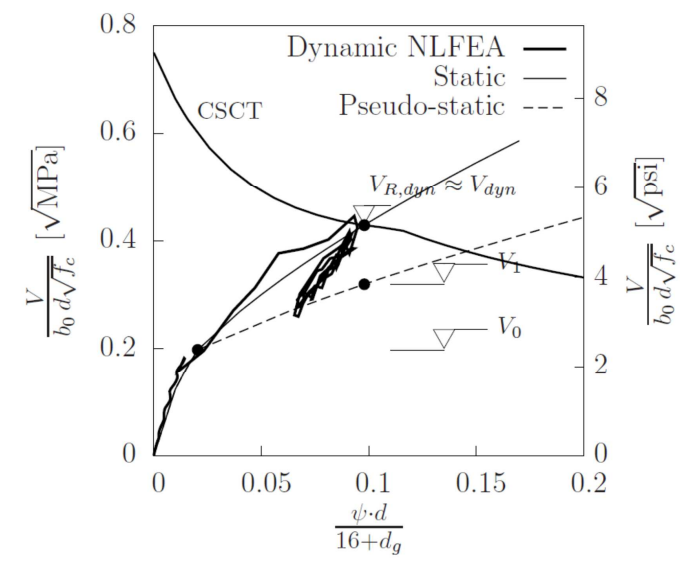

Figure 8 - Application of proposed approach to case study and comparison with dynamic NLFEA ${ }^{10}$ : (a) frequent load combination $(D R=0.9)$ and $(b)$ characteristic load combination $(D R=1.1)$.

\section{CONTRIBUTION OF MEMBRANE ACTION}

\section{Compressive membrane action}

It is well known that compressive membrane action CMA can result in a significant increase in strength and stiffness of concrete flat slabs ${ }^{21,36}$ although its inclusion into theoretical models is not straightforward. Einpaul et $a{ }^{35}$ showed that CMA around the supports can develop in continuous flat slabs with low amounts of hogging (negative) flexural reinforcement due to cracking and subsequent restraint dilatancy. Einpaul ${ }^{38}$ also showed that this effect, which leads to a stiffer load-rotation response, can be taken into account by introducing a factor in the parabolic load-rotation equation in Model Code 2010 which depends on the ratio between the cracking moment and the flexural strength in the support strip. For column removal situations, the compressive membrane action in the slab around the removed column can be significant (Keyvani et al. ${ }^{39}$ ) due to restraint dilatancy after substantial cracking which is expected as the slab is not designed to resist sagging (positive) moments in this region. This effect can cause a relative horizontal movement between the adjacent supports pushing them away from each other. Keyvani et ll. $^{39}$ obtained compressive membrane forces at the adjacent column of the order of $700 \mathrm{kN} / \mathrm{m}$ (48 kip/ft) for span lengths after column removal of $L_{1}=12 \mathrm{~m}$ ( $39 \mathrm{ft}$ ); the flat plate studied by Olmati et al. ${ }^{10}$ shown in Fig. 5 predicted compressive membrane forces along line (2) at column $\mathrm{B} 2$ of around $550 \mathrm{kN} / \mathrm{m}$ (37 kip/ft) for the frequent load combination and around $700 \mathrm{kN} / \mathrm{m}$ (48 kip/ft) near the removed column. The increase in flexural capacity in such cases can be relevant and it can contribute significantly in arresting progressive collapse. An example of the arrest of progressive collapse due to CMA of a real building is shown by Keyvani et al. ${ }^{30}$ in which the column removal in a post-tensioned concrete flat slab structure resisted progressive collapse with a relatively small permanent maximum vertical deflection $u_{\text {dyn }} \approx$ $L_{1} / 300$. Further research is needed on CMA and its modelling for general slab configurations. 
2 The development of tensile membrane action due to geometry nonlinearity after large deformations has often been claimed as an effective defense mechanism to arrest progressive collapse (e.g. Hawkins and Mitchell ${ }^{1}$ ). In fact, the tying force approach adopted in codes of practice is intended in many cases to provide resistance to gravity loads relying solely on tensile membrane action. As discussed by ${ }^{7,18}$, an ideal efficient design for normal load cases in which the suddenly applied gravity loads exceeds the plastic resistance of the system would require a significant development of membrane action. This is shown schematically in Fig. 9(a) from ${ }^{7,18}$ by the shaded areas representing the work done by the load and the internal energy required for stability of the system. In flat slabs, lateral constraint can be provided by the continuity of the slab, however the development of tensile membrane action might be preceded by punching around the supports.

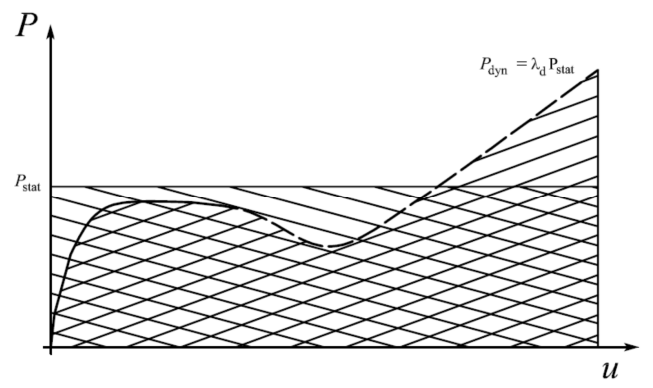

(a)
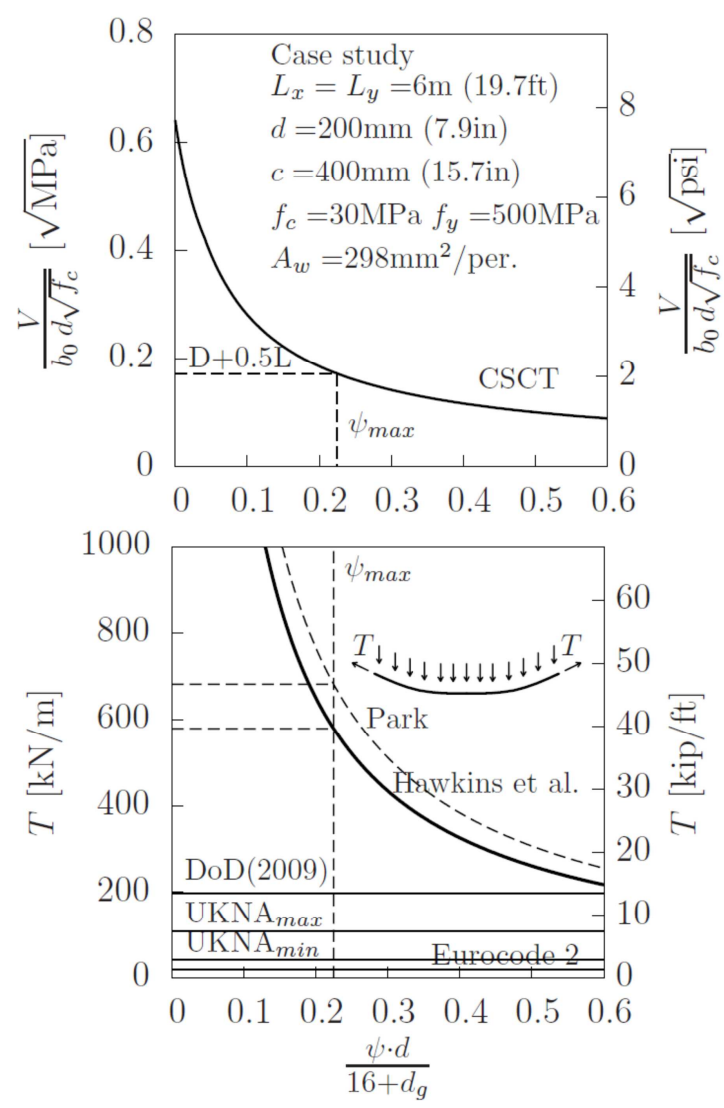

(b)

\section{Figure 9 - Tensile membrane action: (a) balance between work done and internal energy for gravity static load above the plastic resistance ${ }^{6}$ and (b) calculation of membrane forces to resist gravity loads.}

The limitation of tensile membrane action due to punching has not been well defined in the past as the development of tensile membrane forces and punching has not been investigated in combination. Qian and $\mathrm{Li}^{20}$ showed experimentally that in order to develop significant tensile membrane action, mitigating actions need to be put in place to avoid punching (e.g. column drops). In this section, the development of tensile membrane forces is investigated using two widely accepted analytical membrane models developed by Park ${ }^{40}$ and Hawkins 
and Mitchell ${ }^{1}$ both providing relatively similar results of membrane forces. These models are used in combination with the CSCT since membrane action and punching capacity can therefore be written in terms of the slab rotation near the column using the compatibility relationship $u \approx 1.5 L_{0} \psi$. Park's model is given by Eq. (6) for a square plate with equal yield membrane forces of the reinforcement in each direction which is placed over the whole area of the slab.

$$
\frac{q L^{2}}{T u}=\frac{\pi^{3}}{4 \sum_{n=1,3,5 \ldots}^{\infty} \frac{1}{n^{3}}(-1)^{\frac{n-1}{2}}\left(1-\left[\cosh \left(\frac{n \pi}{2}\right)\right]\right)} \approx 13.6
$$

where $q$ is the uniformly distributed load in the slab and $T$ is the tensile membrane force. Similarly, Hawkins and Mitchell's model is given by Equations (6) and (7) as a function of the strain along the membrane $\varepsilon$ :

$$
\begin{aligned}
& T=\frac{q L}{4 \sin \sqrt{6 \varepsilon}} \\
& u=\frac{3 L \varepsilon}{2 \sin \sqrt{6 \varepsilon}}
\end{aligned}
$$

Both membrane models predict (from basic equilibrium considerations) that for larger slab rotations at the boundaries, lower tensile membrane forces are required to balance the gravity loads (Fig. 9(b)). Conversely, if the slab rotation at punching is small, the corresponding tensile membrane forces required will be significant and potentially larger than the prescriptive tying forces used in design. A systematic analysis was carried out to assess the minimum tensile forces that would need to be activated in the slab to resist gravity loads by means of membrane action alone prior to punching. Different case studies were investigated for a regular column layout

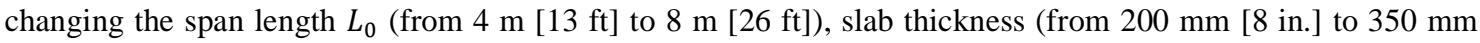
[14 in.]), column size (from $200 \mathrm{~mm}$ [8 in.] to $400 \mathrm{~mm}$ [16 in.]), concrete strength (from $20 \mathrm{MPa}$ [2900 psi] to $50 \mathrm{MPa}$ [7250 psi]) and live loads (from $1 \mathrm{kN} / \mathrm{m}^{2}$ [21 psf] to $5 \mathrm{kN} / \mathrm{m}^{2}$ [105 psf]). The connections were designed systematically for each case according to Eurocode 2 to obtain the required area of flexural and shear reinforcement for the factored live load considered $(1.35 \mathrm{D}+1.5 \mathrm{~L})$. For the amount of shear reinforcement obtained in each case, the corresponding punching strength-rotation curve was obtained according to the failure criterion of the CSCT as shown in Fig. 9(b). This curve was then used to obtain the maximum slab rotation that a slab could ever achieve near the connection $\psi_{\max }$ for an accidental gravity load combination (frequent combination $\mathrm{D}+0.5 \mathrm{~L}$ ). The rotation $\psi_{\max }$ was then used to assess the corresponding minimum tensile membrane force required according to each membrane model as shown in Fig. 9(b).

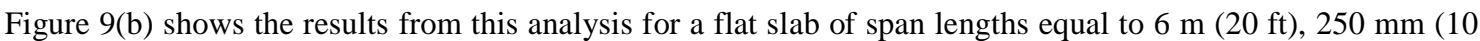
in.) thick, imposed loading of $4 \mathrm{kN} / \mathrm{m}^{2}(84 \mathrm{psf})$ and $400 \mathrm{~mm}$ (16 in.) square columns in which the minimum tensile force obtained to resist the accidental load combination prior to punching was $680 \mathrm{kN} / \mathrm{m}(47 \mathrm{kip} / \mathrm{ft})$ according to Park's model and $578 \mathrm{kN} / \mathrm{m}$ (40 kip/ft) according to Hawkins and Mitchell's model. The corresponding maximum rotation $\psi_{\max }$ was in this case $36 \mathrm{mRad}$. The tensile force obtained is significantly larger than the tying forces required in UK provisions in the National Annex to Eurocode 2 (tying force varies in this case from $43 \mathrm{kN} / \mathrm{m}$ (3 kip/ft) to $108 \mathrm{kN} / \mathrm{m}$ (7 kip/ft) depending on the number of stories); tying force requirements in Eurocode 2 give even lower values to those in UK National Annex. For this case DoD provisions for tying forces of flat slabs give a value near $200 \mathrm{kN} / \mathrm{m}(14 \mathrm{kip} / \mathrm{ft})$ which is again significantly lower than the membrane force needed to balance the gravity loads.

The parametric analysis showed that in the large majority of the cases considered punching would occur prior the required level of rotation to form a pure tensile membrane with the required specified tying forces. Although under a true column loss event other mechanisms may work to prevent progressive failure, the use of prescriptive tie requirements may provide a false sense of security to a designer if they neglect to check ductility capacity. It is apparent that further work is needed to investigate the tying force provisions in codes and its applicability to flat slab systems. In particular, the introduction of ductility conditions would need to be considered for different types of construction. With this respect, guidelines by $\mathrm{DoD}^{16}$ in its latest version (2009) seem to go in this direction by giving rotation limits at the connections for frame structures; however for flat slabs further work is needed. As discussed in next section, the assessment of ductility of the connections in flat slabs is related to the post-punching response which is an under-researched field.

\section{MODELLING POST-PUNCHING RESPONSE}

The post-punching response of the connection can contribute significantly towards arresting progressive collapse due to the residual capacity and ductility which could potentially allow the development of alternative load paths such as tensile membrane action (Fig. 9(a)). Work on post-punching is scarce and it has traditionally

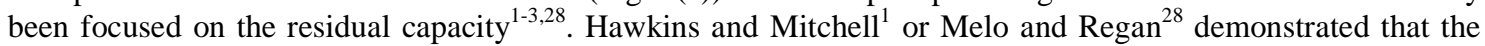
tensile reinforcement at the top of the slab in the connection has a negligible contribution to the post-punching 
residual strength. Tests by Fernández Ruiz et l. $^{3}$ showed that slabs with tensile reinforcement alone could develop post-punching strengths of around $30 \%$ of the punching strength whereas slabs with tensile reinforcement and integrity reinforcement at the compression zone could have a residual strength of $70 \%$; these results are consistent to those given in the CIRIA report ${ }^{2}$. The early work by Regan led to the recommendation which is also adopted in ACI $318^{17}$ detailing rules for structural integrity of using at least two reinforcement bars in each direction passing through the column at the bottom of the slab.

7 The development of analytical models for post-punching is problematic as discussed by ${ }^{3,29}$ due to the large number of parameters affecting the localized damage of the concrete around the reinforcement bars which often requires several assumptions based on experimental evidence. The use of numerical models can provide additional information regarding the deformation capacity of the connection after failure which can be critical in the assessment of structural robustness. The development of numerical tools to model post-punching behavior requires significant validation and verification against experimental data. Some modelling techniques of postpunching were presented by Keyvani et $a l .{ }^{39}$ in which the flexural and integrity reinforcement was modelled explicitly using connector (Cartesian-Cardan elements) between the slab and the assumed punching cone. Liu ${ }^{4}$ also used beam connector to model post-punching in the system model. A difficulty of such techniques is the definition of the constitutive relationships used in the connectors based on pre-punching and post-punching shear transfer mechanisms which are uncertain and difficult to assess individually. Alternative techniques include the use of solid elements with discrete modelling of the reinforcement as presented in this section.

Tests PM4 and PM12 by Fernández Ruiz et al. ${ }^{3}$ without and with integrity reinforcement respectively were modelled by the authors using LS-DYNA with solid elements as shown in Fig. 10. The FE models included only one quarter of the test specimen due to symmetry. An explicit solver was adopted in the analysis with a displacement control approach (gradual increase of vertical displacement $w$ applied). The solid element consisted of eight-noded hexahedral elements with a constant stress solid element formulation. The constitutive model adopted for the concrete was the Winfrith plasticity concrete model with linear strain softening in tension based on the fracture energy. The reinforcement was modelled explicitly as one dimensional beam elements embedded in the concrete elements with a Lagrange solid constraint (perfect bond) which provided reasonable predictions as the reinforcement of the specimens considered was well-anchored and the localized damaged of the concrete near the reinforcement was taken into account directly in the model. Figures 10(b) and (c) show that FE models captured the punching and post-punching strength of the tests considered and were also able to capture the increase in post-punching capacity and stiffness due to the provision of integrity reinforcement. Whilst complex, the modelling of post-punching using solid elements is a promising tool and could potentially be used in the future to assess different detailing configurations proposed in design against progressive collapse.

(a)

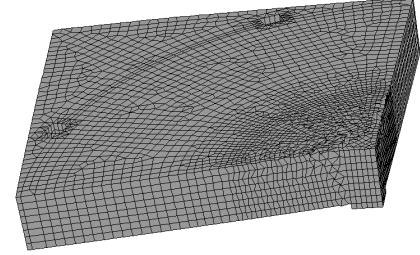

(b)

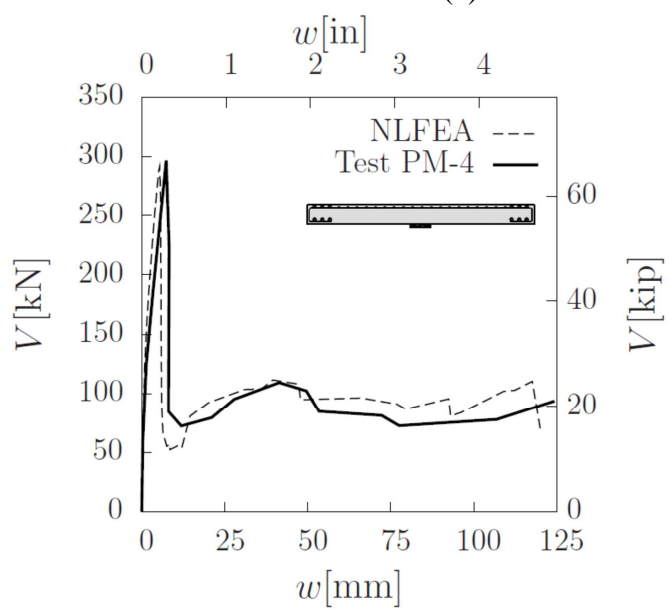
specimen and deformations after punching, (b) and (c) comparison between experimental and numerical predictions of residual strength for tests PM-4 and PM-12 respectively (tests by Fernández Ruiz et al. ${ }^{4}$ ). 
2 Structural robustness of reinforced concrete flat slabs and their susceptibility to progressive collapse is highly influenced by the structural performance of the column-slab connections. This paper presents a simplified approach to assess punching of adjacent columns in a sudden column removal scenario, which is commonly used in the assessment of structural robustness. The main conclusions from this work are:

1. Using load-deformation based formulae for punching (e.g. CSCT) is particularly useful for accidental loading and dynamic situations, as shown in this work. Such approaches allow consideration of inertial effects and apply energy based principles which can be used to assess dynamic punching cases governed either by the local or global response. These situations are commonly found in progressive collapse analyses of flat slab buildings for different triggering events (e.g. column damage, punching around the connection, slab impacting from above and blast).

2. The sudden column removal scenario used in practice as a simple dynamic test of structural robustness of the system, introduces a significant increase in the demand-capacity ratio of the adjacent columns due to dynamic amplification of the reactions (demand) and reduction of the punching capacity due to the dynamic amplification of the deformations (global response). It is shown that adopting a constant dynamic amplification factor for the reactions equal to 2 , as recommended in practice for concrete structures, can lead to overly conservative results which justifies the need to carry out a more rigorous dynamic assessment.

3. The proposed formulae for punching assessment under sudden column removal situations based on the DRA and CSCT gives a simple but theoretically sounded solution which considers the main parameters involved (i.e. dynamic effects on demand and capacity, increase in both moment transfer and slenderness after column removal). The proposed pseudo-static relationship enables the introduction of analogous concepts for quasi-static punching such as the definition of an increased pseudo-static slenderness in the shear demand to rotation formula in Model Code 2010. The proposed method can take into account strain-rate effects (in demand and capacity) and can also be formulated in a LoA format so that it could easily be implemented in codes of practice.

4. The punching predictions for the case study presented using the proposed approach are consistent with those obtained using a more refined dynamic NLFEA. The case study investigated confirms that column removal is not always critical. The load dynamic amplification factor formula obtained from energy balance considerations provides similar results to those observed experimentally and numerically for flat slabs with similar levels of gravity loads. The proposed formula for $\lambda_{d}$ is only valid for punching assessment of an individual connection and does not consider the development of tensile membrane action (high-ductility).

5. The analysis carried out in this paper using different widely accepted tensile membrane models in combination with the CSCT confirms that punching occurs prior the required level of slab rotation to form a pure tensile membrane with the specified tying forces in codes of practice. Further work is needed to confirm the potential development of tensile membrane action after punching in flat slabs, which is challenging as it is highly influenced by detailing of the reinforcement in the slab crossing the column. The numerical models presented in this work using solid FE models provide a promising tool to address this problem, although they are complex as the flexural and integrity reinforcement needs to be modelled explicitly.

6. The analytical and numerical tools presented in this work can be used in different alternative load path analyses which are commonly used in the assessment of structural robustness. The use of the DRA and the CSCT is promising in terms of assessing the arrest of progressive collapse of concrete flat slab structures as both approaches are highly compatible. These approaches can potentially be used for more realistic scenario-dependent analyses.

\section{ACKNOWLEDGMENTS}

The work is a continuation of a research project financially supported by the Engineering and Physical Sciences Research Council EPSRC, Impact Acceleration Account (IAA) held by the University of Surrey (grant ref: EP/K503939) linked with a previous project funded by EPSRC of the UK (grant ref: EP/K008153/1). The authors would also like to acknowledge project collaborators at Arup in the UK (Tony Jones and David Cormie) and EPFL in Switzerland (Aurelio Muttoni and Miguel Fernández Ruiz) for their feedback and technical discussions on the topic. The valuable feedback from Bassam Izzudin from Imperial College London is also acknowledged. 
2 1. Hawkins, N. M., and Mitchell, D., "Progressive Collapse of Flat Plate Structures", ACI J. Proceedings, V. 76, 3 No. 7, 1979, pp. 775-808.

4 2. Regan, P. E., "Behaviour of Reinforced Concrete Flat Slabs", Construction Industry Research and 5 Information Association (CIRIA), Report No. 89, 1981, 88 pp.

6 3. Fernández Ruiz, M.; Mirzaei, Y.; and Muttoni, A., "Post-punching Behavior of Flat Slabs", ACI Structural 7 Journal, V. 110, No. 5, Sept. -Oct. 2013, pp. 812-801.

8 4. Muttoni, A., "Punching Shear Strength of Reinforced Concrete Slabs without Transverse Reinforcement", 9 ACI Structural Journal, V. 105, No. 4, July-Aug. 2008, pp. 440-450.

10 5. Fédération internationale du béton, "fib Model Code for Concrete Structures 2010," Ernst \& Sohn, Berlin, 11 Germany, 2013, 434 pp.

6. Izzudin, B. A,; Vlassis, A. G.; Elghazouli, A. Y.; and Nethercot, D., "Progressive Collapse of Multi-storey Buildings due to Sudden Column Loss - Part I: Simplified Assessment Framework", Engineering Structures, V. 30, 2008, pp. 1308-1318. doi:10.1016/j.engstruct.2007.07.011

7. Izzudin, B. A; and Nethercot, D., "Design-Oriented Approaches for Progressive Collapse Assessment: LoadFactor vs Ductility-Centred Methods", ASCE Structures Congress, Austin, 2009, pp. 800-1791. doi: 10.1061/41031(341)198

8. Vlassis, A. G.; Izzudin, B. A,; Elghazouli, A. Y.; and Nethercot, D., "Progressive Collapse of Multi-storey Buildings due to Sudden Column Loss - Part II: Application”, Engineering Structures, V. 30, 2008, pp. 14241438. doi:10.1016/j.engstruct.2007.08.011

9. Liu, J., "Progressive Collapse Analysis of Older Reinforced Concrete Flat Plate Buildings Using Macro Model", PhD Thesis, University of Nevada, Las Vegas, 2014.

10. Olmati, P.; Sagaseta, J.; Cormie D.; and Jones, A. E. K., "Simplified Reliability Analysis of Punching in Reinforced Concrete Flat Slab Buildings Under Accidental Actions”, Engineering Structures (under review).

11. Minister of Housing and Local Government, "The Building (Fifth Amendment) Regulations 1970", (S.I. 1970, No. 109), Statutory Instruments of the UK, 1970.

12. Department of Communities and Local Government, "The Building Regulations 2010 - Structure: Approved Document A", HM Government, UK, 2010.

13. British Standards Institution (BSI), "BS 8110 Part 1: Structural use of concrete: Code of Practice for Design and Construction", BSI, 1997.

14. EN 1992-1-1:2004, "Design of Concrete Structures-Part 1: General Rules and Rules for Buildings", European Committee for Standardization (CEN), Brussels, Belgium, 2004, 225 pp.

15. General Services Administration (GSA), "Progressive Collapse Analysis and Design Guidelines for New Federal Office Buildings and Major Modernization Projects", Office of Chief Architects, Washington DC, 2000.

16. Department of Defense (DoD), "Design of Buildings to Resist Progressive Collapse (UFC 4-023-03)", Unified Facilities Criteria, Washington DC, 2009.

17. ACI Committee 318, "Building Code Requirements for Structural Concrete (ACI 318-14) and Commentary (ACI 318R-14)," American Concrete Institute, Farmington Hills, MI, 2014, 519 pp.

18. Arup, "Review of International Research on Structural Robustness and Disproportionate Collapse", Department for Communities and Local Government, 2011, 198 pp.

19. Merola, R., "Ductility and Robustness of Concrete Structures Under Accidental and Malicious Load Cases", $\mathrm{PhD}$ Thesis, University of Birmingham, UK, 2009.

20. Qian, K.; and Li, B., "Experimental Study of Drop-Panel Effects on Response of Reinforced Concrete Flat 44 Slabs after Loss of Corner Column", ACI Structural Journal, V. 110, No. 2, March-Apr. 2013, pp. 319-330.

45 21. Qian, K.; and Li, B., "Resilience of Flat Slab Structures in Different Phases of Progressive Collapse", ACI 46 Structural Journal, V. 113, No. 3, May-June 2016, pp. 537-548.

47 22. Russell, J. M.; Owen, J. S.; Hajirasouliha, I., "Experimental Investigation on the Dynamic Response of RC 48 Flat Slabs After a Sudden Column Loss", Engineering Structures, V. 99, 2015, pp. $28-41$. 
23. Szyniszewski, S. T.; Krauthammer, T.; and Yimk, H. C., "Energy Flow Based Progressive Collapse Studies of Moment Resisting Steel Framed Buildings", Final report to US army ERDC, CIPPS-TR-003-2008. Center for Infrastructure Protection and Physical Security, University of Florida, 2009.

4 24. European Cooperation in the field of Scientific and Technical Research (COST), "Robustness of Structures

5 - Proceedings of the $1^{\text {st }}$ Workshop”, ETH Zurich, Switzerland, 2008.

6 25. Micallef, K.; Sagaseta, J.; Fernández Ruiz, M.; and Muttoni, A., "Assessing Punching Shear Failure in 7 Reinforced Concrete Flat Slabs Subjected to Localized Impact Loading”, International Journal of Impact 8 Engineering, V. 71, 2014, pp. 17-33.

9 26. Sagaseta, J.; Olmati, P.; Micallef, K.; and Cormie, D., "Punching Shear Failure in Blast-loaded RC Slabs 10 and Panels", Engineering Structures (under review)

27. Mitchell, D.; and Cook, W. D., "Preventing Progressive Collapse of Slab Structures", Journal of Structural Engineering ASCE, V.110, No.7, 1984, pp. 1513-1532.

28. Melo, G. S.; and Regan, P. E., "Post-Punching Resistance of Connections between Flat Slabs and Interior Columns," Magazine of Concrete Research, V. 50, No. 4, Dec. 1998, pp. 319-327.

29. Habibi, F., "Post-Punching Shear Response of Two-Way Slabs", PhD Thesis, McGill University, Montreal, Canada, 2012.

30. Keyvani, L.; and Sasani, M., "Analytical and Experimental Evaluation of Progressive Collapse Resistance of a Flat-Slab Posttensioned Parking Garage”, ASCE Journal of Structural Engineering, V. 141, No. 11, 2014.

31. EN 1990:2002, "Eurocode - Basis of Structural Design” European Committee for Standardization (CEN), Brussels, Belgium, 2002, 115 pp.

32. Einpaul, J.; Bujnak, J.; Fernández Ruiz, M.; and Muttoni, A., "Study of Influence of Column Size and Slab Slenderness on Punching Strength", ACI Structural Journal, V. 113, No. 1, Jan. -Feb. 2016, pp. 135-145. doi: $10.14359 / 51687945$

33. Delhomme, F.; Mommessin, M.; Mougin, J. P.; and Perrotin, P., "Simulation of a Block Impacting a Reinforced Concrete Slab with a Finite Element Model and a Mass-spring System", Engineering Structures, V.29, No.11, 2007, pp. 2844-2852

34. Concrete Society, "Guide to the Design and Construction of Reinforced Concrete Flat Slabs", Technical Report, No. 64, 2007, 101 pp.

35. Einpaul, J.; Fernández Ruiz, M.; and Muttoni, A., "Influence of Moment Redistribution and Compressive Membrane Action on Punching Strength of Flat Slabs", Engineering Structures, V. 86, 2015, pp. 43-57. doi: 10.1016/j.engstruct.2014.12.032

36. Sagaseta, J.; Muttoni, A.; Fernández Ruiz, M.; and Tassinari, L., " Non-axis-symmetrical Punching Shear Around Internal Columns of RC Slabs Without Transverse Reinforcement", Magazine of Concrete Research, V.63, No.6, 2011, pp. 441-457. doi: 10.1680/macr.10.00098

37. Collings, D.; and Sagaseta, J., "A Review of Arching and Compressive Membrane Action in Concrete Bridges”, Proceedings of the Institution of Civil Engineers - Bridge Engineering, 2015. 10.1680/bren.14.00039

38. Einpaul, J., "Punching Strength of Continuous Slabs", PhD Thesis, EPFL, No. 6928, Lausanne, Switzerland, 2016, 178 pp.

39 39. Keyvani, L.; Sasani, M.; and Mirzaei, Y., "Compressive Membrane Action in Progressive Collapse 40 Resistance of RC Flat Plates”, Engineering Structures, V. 59, 2014, pp. 554-564.

41 40. Parke, R., "Tensile Membrane Behaviour of Uniformly Loaded Rectangular Reinforced Concrete Slabs with 42 Fully Restraint Edges”, Magazine of Concrete Research, V. 16, No. 46, 1964, pp. 39-44. 